\title{
Drivers and Barriers to Clean Cooking: A Systematic Literature Review from a Consumer Behavior Perspective
}

\author{
Vania Vigolo*(D), Rezarta Sallaku and Federico Testa \\ Department of Business Administration, University of Verona, Via Cantarane, 24, 37129 Verona, Italy; \\ rezarta.sallaku@univr.it (R.S.); federico.testa@univr.it (F.T.) \\ * Correspondence: vania.vigolo@univr.it; Tel.: +39-045-8028624
}

Received: 6 October 2018; Accepted: 18 November 2018; Published: 21 November 2018

\begin{abstract}
A lack of access to clean energy and use of traditional cooking systems have severe negative effects on health, especially among women and children, and on the environment. Despite increasing attention toward this topic, few studies have explored the factors influencing consumers' adoption of improved cooking stoves (ICS). This systematic literature review $(n=81)$ aims to identify the main drivers and barriers to clean cooking from a consumer perspective. In addition, it aims to define how consumers perceive ICS with respect to traditional stoves. Thematic analysis revealed seven factors that may act as drivers or barriers to ICS adoption: economic factors; socio-demographics; fuel availability; attitude toward technology; awareness of the risks of traditional cookstoves and the benefits of ICS; location; and social and cultural influences. Perceptions focused on four topics: convenience and uses, aesthetics, health-related impacts, and environmental impacts. This review contributes to understanding of consumer behavior with regards to ICS. The findings suggest that availability and affordability of technology are not enough to enhance ICS adoption. Rather, policy makers and managers should approach customers with a less technical and a more personalized approach that takes due consideration of a local context and its social and cultural dynamics.
\end{abstract}

Keywords: clean cooking; energy poverty; consumer behavior; purchase intention; improved cooking stoves; health; environment; sustainability; social norms; culture

\section{Introduction}

Almost three billion people in the world lack access to energy infrastructure and use biomass solid fuels such as wood, charcoal, crop residues or dung for cooking [1]. Besides being highly inefficient, these traditional, open-fire cooking methods produce toxic particulates that cause household air pollution and contribute to around 4 million premature deaths per year [2], especially among women and children [3]. In fact, because of social and cultural norms, in certain countries women spend most of their time in the home with children, so these two groups are more liable than men to breathe in the unhealthy smoke [4]. Severe impacts on health are not the only effects of the use of traditional cookstoves. For example, the emissions produced by the combustion of solid fuels also have a negative impact on the environment and contribute to global climate change, and intense use of firewood for cooking purposes substantially increases deforestation [5]. This situation is not evenly distributed across the world. Rather, energy poverty, described by Bonan et al. (2017) (p. 492) as the "lack, scarcity or difficulty in accessing modern energy services by households," in particular affects rural areas in developing countries in Africa, Asia, and South America [6]. For its high social and environmental implications, clean cooking thus represents a central issue attracting increasing interest from scholars, public institutions, firms, and organizations. 
In recent decades, global institutions, international development agencies, local governments and the private sector have worked to promote the diffusion and adoption of cleaner cooking solutions [7]. Since access to energy infrastructure and modern cooking alternatives is still limited in several countries, biomass remains the most practical fuel for the near future. Within this scenario, improved cookstoves (ICS) could represent an intermediate step on the energy ladder toward cleaner and more sustainable solutions [8]. Improved cookstoves or improved cooking stoves are devices that burn biomass, but are designed "to maximize thermal and fuel efficiency, operate safely and minimize emissions harmful to human health" [5] (p. 626), thus improving the sustainability of cooking processes. The term 'improved cookstove' refers to a range of different cooking technologies that may have different degrees of performance and cost [9]. The design of cookstoves also varies according to location and the type of fuel available: for example some ICS are designed to burn only one type of fuel, while others can burn a variety of fuels [5]. Despite several ICS programs operating worldwide, the adoption and sustained use of ICS remains low among households [10-12]. An increasing number of scholars has addressed this topic from a variety of perspectives, focusing for example on stoves' technical characteristics and performance, on fuel availability or public policy interventions. Some empirical studies have also explored the factors influencing the adoption of ICS. However, to increase the diffusion of more sustainable cooking behavior among households in developing countries, there is a need to improve understanding of consumers' cooking choices, in particular with regards to the factors affecting the use of ICS. This study aims to address this knowledge gap by conducting a systematic literature review about the determinants of ICS adoption from a consumer behavior perspective. A systematic literature review is a type of secondary data analysis that represents a transparent and reproducible methodology "that locates existing studies, selects and evaluates contributions, analyses and synthesizes data, and reports the evidence in such a way that allows reasonably clean conclusions to be reached" (Denyer and Tranfield, 2009, p. 671) [13].

Some systematic literature reviews on clean cooking from the demand-side perspective have already been published. For example, Lewis and Pattanayak (2012) analyzed 32 papers to identify the determinants of fuel and stove choice [14], while Puzzolo et al. (2016) reviewed 44 studies focusing on the adoption of clean fuels [15]. Recently, Bonan et al. (2017) conducted a review to identity the barriers to and drivers of the adoption of different types of clean fuels and their impact on economic development and poverty reduction; however they did not adopt a systematic approach [6]. Despite the importance of these contributions, there is a need to provide a more comprehensive analysis of the factors affecting the adoption of ICS and the distinctive traits of ICS versus traditional stoves from a consumer perspective. Specifically, by adopting a systematic approach, this study addresses the following research questions:

(1) What are the drivers and barriers that influence consumers' adoption of ICS?

(2) How do consumers perceive ICS in comparison with traditional cooking stoves?

The findings of this review will contribute to systematizing knowledge about consumer behavior in this specific context and have practical managerial and policy implications for supporting the adoption of more sustainable cooking behaviors. The remainder of the paper is organized as follows. First, Section 2 describes the methodology employed in the study, explaining how the materials were collected, selected and analyzed. Section 3 then presents the descriptive results of the analysis and the main themes that emerge from the literature review. Section 4 provides discussion and implications, while Section 5 presents the limitations of the study and proposes future research directions.

\section{Methodology}

In the context of sustainability studies, the systematic literature review approach has been adopted with regards to various research topics including the circular economy [16,17], logistics service providers and supply chain management $[18,19]$, sustainable innovation $[20,21]$, and sustainable consumption [22]. 
From a methodological perspective, a systematic literature review involves several steps [13] [16]:

(1) research question formulation and definition establish the focus of the literature review (as described in Section 1);

(2) location of documents as materials for review (Section 2.1);

(3) article selection and evaluation via the application of selection criteria to identify documents relevant to the scope of the study (Section 2.2);

(4) analysis and synthesis, which involves evaluation and comparison of the selected articles to make associations and rearrange "knowledge that is not apparent from reading the individual studies in isolation" [11] (p. 685) (Section 2.3).

\subsection{Locating Studies}

Material collection was carried out through Scopus and Web of Science (WoS), which are regarded among the most comprehensive and authoritative scientific databases [16]. After reading several publications on the general topic and based on the authors' experience, three main terms were selected as search criteria to be employed in both databases:

(1) "clean cooking" OR

(2) "improved cook* stove*" OR

(3) "improved cookstove*."

In the WoS Core Collection, which includes SCI-EXPANDED, SSCI, A\&HCI, CPCI-S, CPCI-SSH, and ESCI, the field chosen to search was "Topic" (covering Title, Author Keywords, Abstract, Keyword Plus ${ }^{\circledR}$.), while in Scopus the chosen field was "Title, Author Keywords, Abstract". For both databases, the results were limited to document types "Article" and "Review". As recommended in the literature, only journal articles were selected, which improves the rigor and quality of a literature review [23-25]. Finally, only manuscripts written in English were selected as English is generally considered the international academic language [16]. No chronological restriction was employed. Overall, WoS returned 340 results and Scopus 386, giving a total of 726 documents.

\subsection{Study Selection and Evaluation}

Of the total 726 documents, 275 overlapped between the two databases. After deleting duplicates, the authors screened 451 abstracts to begin material selection. As the focus of this research is consumer behavior, 335 articles concerning strictly environmental issues (e.g., $\mathrm{CO}_{2}$ emissions), engineering/technical aspects (e.g., stove or fuel performance), or health-related problems (e.g., pre-term delivery among pregnant women) were excluded, thus reducing the data set to 116 documents. After reading the full text of each article, 35 were excluded because they were not relevant for this research, which focuses on the drivers and barriers to ICS adoption and on consumers' perceptions about clean cooking. The final data set thus consisted of 81 papers (Figure 1). 

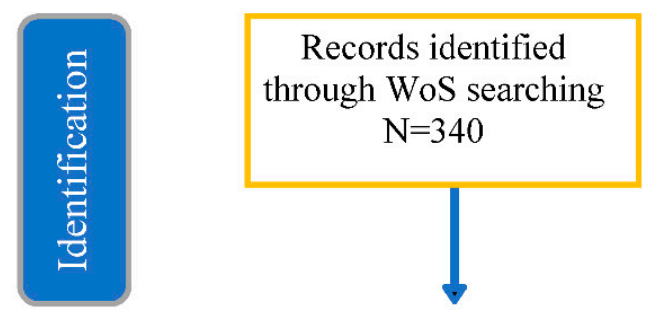

Records identified through Scopus searching $\mathrm{N}=386$
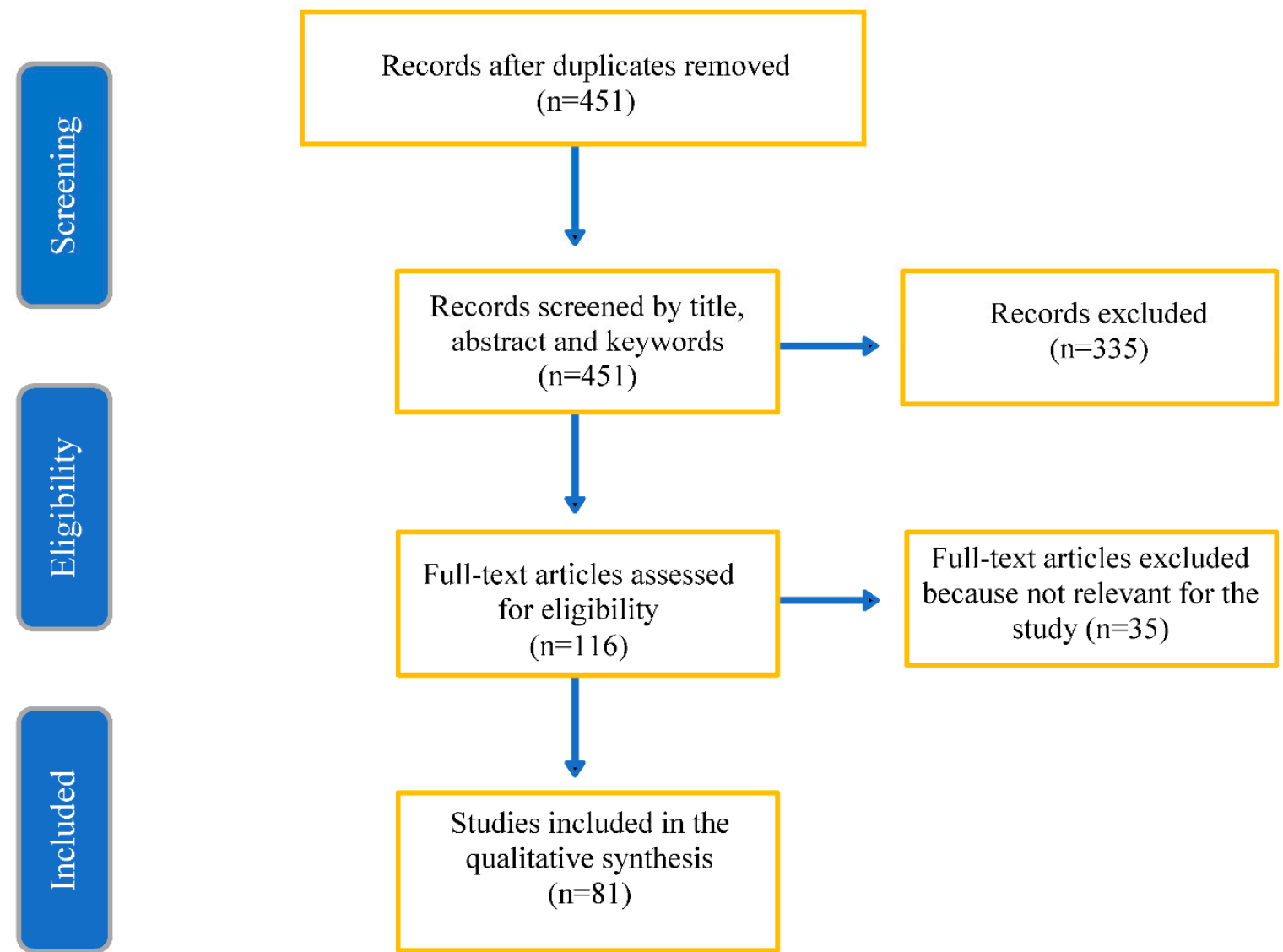

Figure 1. Flow diagram.

\subsection{Analysis and Synthesis}

Following Merli et al. (2018), the full text of articles was analyzed in several steps [16]. First, the researchers established analytical categories adapted from Siva et al.: year, publication, type of article, methodology adopted (Table 1) [26]. Second, two of the researchers independently analyzed and classified each article based on these categories, and later discussed ambiguous cases to avoid any misinterpretation. Third, thematic analysis was conducted with the support of NVivo 11 Plus to explore and identify the main drivers and barriers to ICS adoption and the perceptions of consumers regarding clean cooking options versus traditional cookstoves. Following Orzes et al. (2018), the coding process employed a deductive-inductive approach; that is, the main categories (i.e., drivers, barriers and perceptions) were identified a priori by the researchers (deductive approach), whereas the specific themes within each category emerged during the coding process (inductive approach) [23]. 
Table 1. Analytical categories.

\begin{tabular}{cl}
\hline Category & \multicolumn{1}{c}{ Description of Category } \\
\hline Year & The year in which the article was published \\
Publication & The name of the journal in which the article was published \\
Type & Type of article (empirical paper, literature review or conceptual paper) \\
Methodology & The methodology adopted in the study (qualitative, quantitative or mixed-method) \\
\hline
\end{tabular}

\section{Findings}

\subsection{Distribution and Evolution of the Topic}

Based on the analytical categories previously defined, it is possible to depict how this research topic has developed in the last decades. Even if the first paper on clean cooking relevant for this review was published back in 1984 [27], database analysis shows that academic interest on clean cooking has been growing only since 2012. About two-thirds (72.84\%) of the records were published in the last four years and a half (between January 2014 and May 2018), with a sharp increase of publications since 2016 (Figure 2).

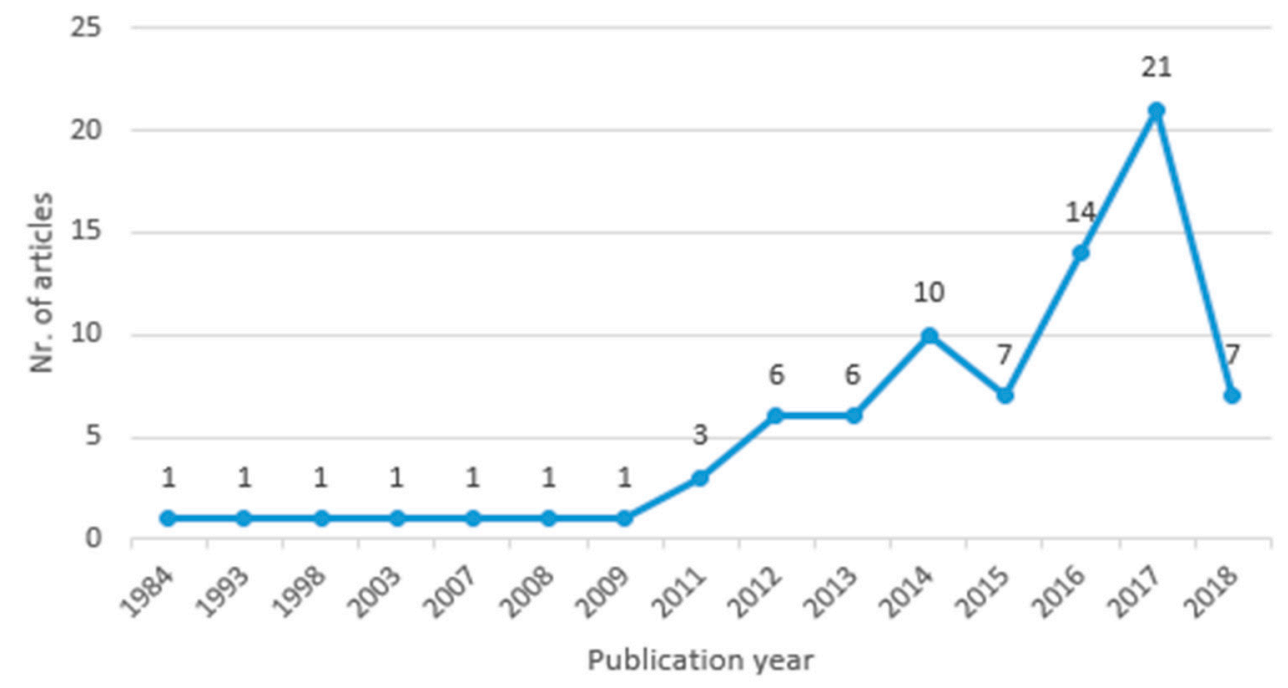

Figure 2. Distribution of articles over time.

With regard to the distribution of articles across sources, the analysis show that clean cooking from a consumer behavior perspective has been addressed in a variety of journals belonging to different subject areas, mainly Energy, Environmental Science, Medicine, Social Sciences, and Economics. Energy Policy is the journal with the highest number of articles published on this topic, followed by International Journal of Environmental Research and Public Health and by Energy for Sustainable Development (Figure 3). Unexpectedly, even though this research topic concerns consumer behavior, only one article was published in a journal belonging to the business, management and accounting subject area, specifically to the marketing category.

In terms of article type, the majority of the reviewed papers are empirical studies $(80.25 \%)$, followed by literature reviews $(14.81 \%)$ and conceptual papers $(4.94 \%)$. From a methodological perspective, $32.1 \%$ of empirical studies adopt a qualitative approach, $51.85 \%$ adopt a quantitative approach, and $16.05 \%$ use a mixed-method approach (combining both qualitative and quantitative methodologies).

As expected, since energy poverty and clean cooking affect in particular developing and emerging countries, all the reviewed studies address specific cities, regions or countries in Africa, Asia, Central and South America. 


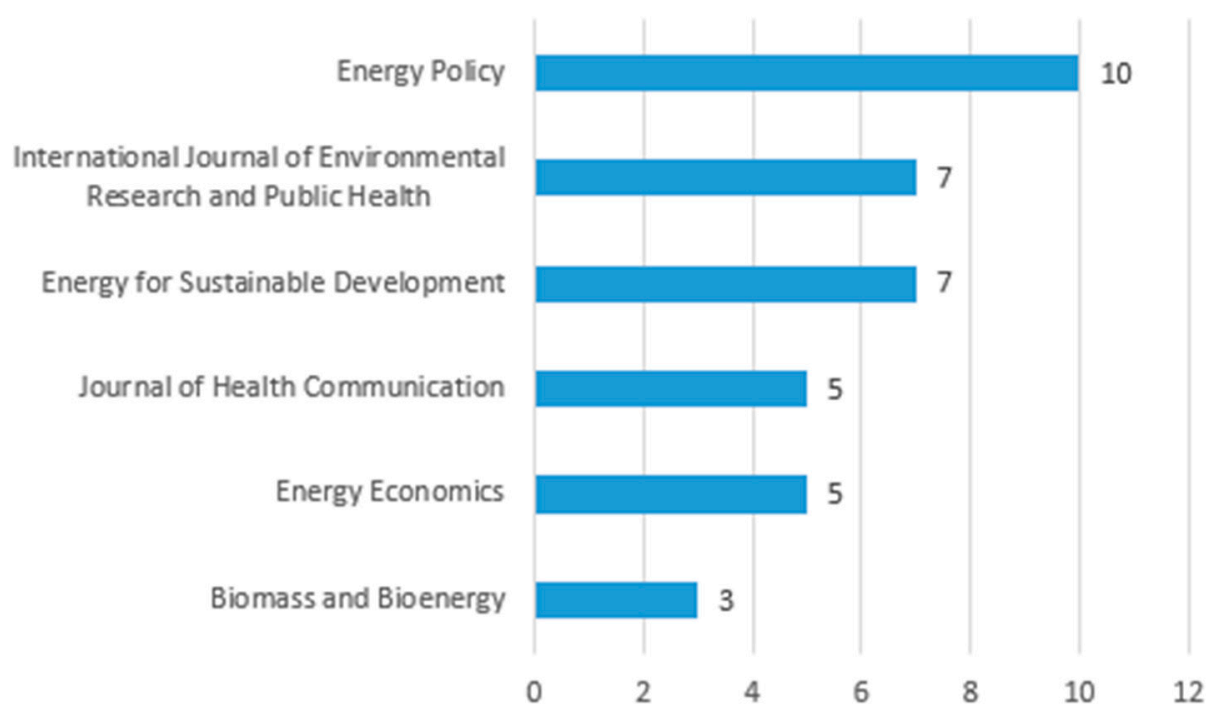

Figure 3. Journals where articles were published.

\subsection{Thematic Analysis}

\subsubsection{Drivers and Barriers to Improved Cooking Stoves (ICS) Adoption}

Thematic analysis revealed seven main variables that may affect choice of a cooking system: economic factors; socio-demographics; fuel availability; attitude toward technology; awareness of the risks of traditional cooking stoves and the benefits of ICS; location; and social and cultural influences. The effect of each of these variables on ICS adoption may differ according to context. Thus, each variable is presented here with an emphasis on its role as a driver or a barrier to ICS depending on the studies considered in the literature review.

\section{Economic Factors}

Economic factors represent a major element influencing ICS adoption. Since energy poverty and limited clean cooking is largely a concern of developing and emerging countries [28], income seems to have a major role in consumer behavior. There is general agreement that household income represents a driver for the adoption of ICS [10,15,28-39]. Higher-income households adopt sustainable cooking systems more frequently than do lower-income households. A higher level of income influences the alternative fuels used and offers more possibilities for families to adopt improved cooking systems [30,33,38,40,41]. For example, Lee (2013) found a direct relationship between income and non-solid fuel (e.g., electricity) consumption [28]. Low income is, therefore, considered a barrier because switching to ICS incurs further financial difficulties for households [42].

In addition, the price of ICS has been found to affect the decision to switch to more sustainable cooking systems $[37,43,44]$. The price of clean technologies is often a prohibitive factor and a primary reason for non-adoption. It is generally very high relative to the household's purchasing power, especially in lower-income communities [15,43,45-50]. In this regard, a recent study conducted in rural Tanzania by Kulindwa et al. (2018) found that an increase in the price of ICS reduces its adoption by $17 \%$, even though the demand for ICS increases when it is supplied on credit [44]. Conversely, Maré and Annegarn (2017) found that availability of credit is not relevant in influencing purchasing behavior [51]. Despite some exceptions, it can be argued on the basis of the literature analysis that financial constraints deriving from low income, limited or no access to credit, high price and low affordability of ICS represent a barrier to the diffusion of sustainable and efficient cooking stoves, facilitating the maintenance of the status quo in terms of traditional cooking systems $[7,40,42,50,52-54]$. 
Socio-Demographics

Socio-demographics (e.g., gender, age, education, household composition) have been extensively explored in studies concerning ICS adoption, and their importance in consumer behavior is widely recognized. However, there is no general agreement about how these variables affect ICS adoption. For example, with regards to gender, several studies [47,55-58] emphasize that women are more likely to use ICS than men, but often they do not have the sufficient authority and economic power within the household to impose their decision on men [6,8]. Van der Kroon et al. (2014) explain that ICS adoption is generally more favorable to women because they are the primary users and beneficiaries of cooking innovations and because, in some societies, the kitchen is considered the domain of women [8].

The role of gender may also vary depending on whether the household is male headed or female headed. For example, in a study conducted in India by Brooks et al. (2016) the use of ICS was positively related to female-headed households [29]. Similarly, Mamuye et al. (2018) found that in Ethiopia, women were more likely to adopt ICS in female-headed households than were married women of male-headed families [59]. Conversely, Mohapatra and Simon (2017) found a direct negative effect of female headship on ICS adoption [3].

Education seems to play a major role in increasing modern fuel consumption and at the same time reducing biomass use [60]. There is general agreement that more highly educated people tend to adopt ICS more frequently than do less-educated people, both men and women $[3,15,29,30,32,35,37,38,45,47,52,57,61-68]$. For example, a recent study by Jan et al. (2017) demonstrates a significant effect of primary or secondary education level on the adoption of ICS in Pakistan compared with no education [10]. Exceptionally, Troncoso et al. (2007) found that education is not a key element of ICS adoption in rural Mexico [61], where women seem likely to become the early adopters if they have an open mind and not necessarily if they have many years of formal education. In line with these results, Kulindwa et al. (2018) found no significant effect of education on ICS adoption in rural Tanzania [44].

With regards to the role of age, different perspectives have emerged among scholars. Some studies have found that younger individuals are more likely to use sustainable cooking systems than are older individuals. For example, Muneer and Mohamed (2003) identified a significant negative effect of a married woman's age on her household's innovativeness in terms of ICS adoption [47]. In other words, the older the woman, the greater her intention to stick to traditional cooking systems. Similarly, it has been found that the age of the main cook acts as a barrier to the use of sustainable clean cooking systems. This negative effect of age may be caused by younger persons tending to experiment more than older persons [41] and the fact that it is more difficult to change long-developed cooking behaviors [69]. In addition, Mohapatra and Simon (2017) found a significant indirect negative effect of the male household head's age on adoption via a reduction in women's intra-household influence [3]. According to these studies, the younger the individual, the higher their propensity to adopt ICS. Conversely, other studies maintain that older age may increase ICS adoption. For example, in northern India, Brooks et al. (2016) found that older and female heads of households are associated with higher use of ICS than younger and male heads [29]. These findings are corroborated by a recent study conducted in rural Tanzania [44].

Household composition also emerged as a factor affecting the use of ICS. In particular, household size (i.e., the number of family members living in the same house) has sometimes been found to influence the decision on whether to adopt sustainable cooking options. Family size can vary greatly in developing and emerging countries. For example, Miah et al. (2009) distinguished between very small (composed of 3-4 individuals), small (5-6 individuals), medium (7-8 individuals), large (9-10 individuals) and very large households (11-12 individuals) [33]. Some scholars have found that household size may have a negative effect on ICS adoption because sustainable stoves are perceived as too small for large families' cooking needs $[4,29,35]$. In addition, as explained by Mohapatra and Simon (2017) "larger households may be more traditional and, hence, less inclined to adopt modern technologies" [3] (p. 1281). Specifically, in rural India, earlier generations were more 
likely to live together as "joint families" than new generations, who tend to live in smaller independent households [3]. In addition, in a study conducted among ICS adopters and non-adopters, Pine et al. (2011) found that the average non-adopter household size was larger and included more children on average (3.7) than adopter households, which had an average of 3.0 children per household [34]. Recent research conducted by Van der Kroon et al. (2014) also showed that a larger number of adults means abundant labor available for the fuel collection necessary for traditional stoves, thus reducing the intention to adopt ICS [8]. Similarly, Jagger and Jumbe (2016) found that willingness to adopt ICS in Malawi was lower among households with a large labor force for fuel collection [70]. However, other studies find that larger families are more likely to adopt ICS [31,37,71]. In this regard, Onyeneke et al. (2017) state that cooking for a large family group usually requires more time and fuelwood, so large households tend to adopt more efficient cooking technologies than small households [31]. In addition, some scholars suggest that the number of children may represent a driver for the adoption of ICS [29], while others have found that the decision to adopt ICS is not influenced by household size [59] or the number of children in the household [3].

\section{Fuel Availability}

Some studies suggest that fuel availability plays a key role in ICS adoption $[70,72,73]$. For example, the findings of research conducted in Malawi by Jagger and Jumbe (2016) indicate a higher interest in ICS adoption when households have their own forest resources (and, therefore, are interested in conserving them) or use a high proportion of crop residues as fuel (probably because of fuelwood scarcity or lack of access among the lowest-income households) [70]. Conversely, the intention to adopt ICS decreases when households have free access to free fuelwood (e.g., when located near to a forest) [59]. Other studies did not find a significant relationship between fuel availability and intention to adopt ICS [14,74], According to research conducted in rural Mexico, difficult access to firewood is not a driver of ICS adoption, even though ICS could more than halve the requirement for firewood [74].

Attitude Toward Technology

Technology access is often inadequate in developing countries, especially in rural areas [42,61], thus reducing the ability to move from traditional cooking methods to more sustainable options. Sometimes, lack of knowledge about the availability of alternate technologies, rather than lack of availability of ICS for purchasing in a certain area, represents a barrier to ICS adoption $[9,75]$. Regardless of the availability of new cooking technologies, several studies on ICS have focused on technology adoption, showing that consumers' attitudes toward new technologies and innovation in general may affect their decision to purchase ICS [39,76]. Specifically, consumers' resistance toward new technology is associated with a lower intention to adopt new cooking systems. For example, Rehman et al. (2012) found that one of the reasons for not switching to new ICS was reluctance to try an alternative technology [9]. Urmee and Gyamfi (2014) argue that programs aimed at the adoption of ICS fail when customers are afraid of using new technologies [5]. Similarly, Goswami et al. (2017) report that trust in a new technology increases the probability of switching to ICS [77]. A positive attitude toward technology is usually associated with higher social class; for example, an interesting study conducted in India found that lower social classes are more likely to reject traditional technology than elites [39].

\section{Awareness of the Risks of Traditional Cooking Stoves and the Benefits of ICS}

Awareness of the risks associated with traditional cooking stoves also emerged as a factor influencing the adoption of more sustainable cooking systems. These risks relate mainly to health and environmental outcomes. In this regard, Poddar and Chakrabarti, (2016) found that an increase in awareness about the negative health and environmental impacts of traditional stoves determines the choice of more sustainable fuels to reduce such a negative effect [66]. Similarly, Jagger and Jumbe (2016) maintain that awareness of the negative effects on deforestation and forest degradation of biomass reliance increased the probability of ICS adoption among households in Malawi [70]. The results of 
two studies conducted in India indicate low awareness and knowledge among households of the health risks associated with traditional cookstoves, and suggest this acts as barrier to the adoption of liquefied petroleum gas (LPG) stoves [78,79]. Maré and Annegarn (2017) conducted a study in South Africa about the willingness to pay for ICS and found that safety awareness campaigns could significantly increase the demand for more efficient and safer stoves [51]. In general, studies agree that greater awareness of the negative outcomes of traditional cooking may play a positive role in the decisions of household to adopt ICS [10,70,73,80-82]. Nevertheless, some studies raise concerns about the significance of the effect of awareness of health risks for the adoption of ICS. For example, participants in a study conducted in Uganda were aware that ICS produces less smoke, but they did not consider the related health benefits as an important factor in the decision to buy a new stove [49]. Furthermore, a study conducted in India shows that advertisements emphasizing smoke reduction and health-related benefits of ICS did not significantly influence purchase decisions, even though they increased customers' awareness about the dangers of indoor smoke [64]. Hanna et al. (2016) also found that households' willingness to pay for the health improvements derived from a reduction in indoor air pollution is still low [83].

The benefits derived from cookstove characteristics also influence decisions to adopt ICS. In particular, health-related benefits of the use of ICS (e.g., reduced smoke) positively affect the decision to adopt more sustainable cooking systems [43]. In addition, a qualitative study of ICS purchasers conducted in rural Kenya showed that efficiency in terms of fuel used and time saved, together with flexibility in the size of cooking pans, influenced the adoption of ICS [43]. Loo et al. (2016) conducted interviews and focus groups to understand how the characteristics of cookstoves affect ICS adoption [84]. In general, the findings were that features such as efficiency, ease of use, appearance, safety and reduced smoke were the reasons why households prefer ICS to the traditional fire [84]. In general, users are more likely to adopt ICS when they achieve economic savings; for example from reduced fuel collection time and reduced cooking frequency because ICS make it possible to combine different types of cooking activities [85-87]. Furthermore, Maré and Annegarn (2017) emphasize a preference for larger stoves (enabling cooking of two dishes simultaneously) [51]. With regard to barriers to the adoption of new cooking systems, it could be argued that poor design of ICS is a barrier if considered inappropriate in terms of size and instability [73,81]. In addition, mechanical problems or the constant need for repairs discourage the use of ICS [72,87]. Finally, for certain types of clean cooking technologies, such as LPG, households may have some safety concerns that discourage them from buying ICS, as emerged in a study conducted in Peru [88].

\section{Location: Urban Versus Rural}

Location has a significant effect on the type of cooking fuel adopted and differences are particularly evident between urban and rural areas $[89,90]$. Households located in rural areas are less interested in adopting cleaner fuels because of the easier access to alternative biomass sources that are cheaper, whereas in urban and suburban areas the rate of ICS adoption is considerably higher $[14,37,91]$. Nguyen (2017) found that in urban areas women are more likely to adopt ICS because they face the problem of firewood scarcity [92]. Some studies demonstrate that rural location is a barrier to a household switching to cleaner and more sustainable fuels, which are usually more expensive than biomass fuels, and for this reason, traditional stoves are still widely used $[14,50,66]$. For example, Kapfudzaruwa et al. (2017) conducted a study among consumers in South Africa, Senegal, Mali, Malawi and Mozambique and found that, in general, rural households are less aware and capable of affording ICS than are urban consumers [50].

\section{Social and Cultural Influences}

Several studies have shown that social and cultural variables affect customers' decisions about cooking systems. Urmee and Gyamfi (2014) reviewed ICS programs around the world and highlighted 
that the reason for the failure of many such projects might be that none have considered local culture and social background in the target areas [5].

With regards to social influences, some scholars have found that decisions around households' cooking fuel choice are usually directly influenced by the type of cooking fuel used by their peers [70,91]. For example, in a qualitative study conducted in rural Kenya, Person et al. (2012) found that interpersonal communication (i.e., word-of-mouth) among women is a primary persuasive tool to adopt ICS [43]. In addition, Martin et al. (2013) explored motivations for purchase and use of ICS in peri-urban Uganda and found that respondents were positively influenced by the behavior of their neighbors who already owned and used an ICS [49]. Similarly, participants of a focus group conducted in India declared that the behavior of their neighbors and relatives would be most influential in determining their intention to purchase an ICS [57].

It is not only social influences, but also culture that affects cooking choices [82]. As described by Tigabu (2017), positive reputation in terms of compatibility with the cooking culture of a community increases the use of ICS [86]. Cooking practices and taste/dietary preference related to the local culture are involved in decision making about ICS adoption $[4,32,77,88]$. In particular, some studies have found that attachment to the particular taste of food cooked on traditional stoves may act as a barrier to the adoption of LPG stoves $[12,39,61,81]$, highlighting that it is not possible to prepare certain traditional dishes with ICS [88]. For example, Goswami et al. (2017) explain that the preference for a traditionally cooked chapatti (a type of unleavened flatbread) creates a bias against the use of ICS [77]. Hollada et al. (2017) conducted in-depth interviews in Peru and found that when they have time, people enjoy collecting fuel and cooking, and these tasks are often considered valued social opportunities [88].

The findings from Rhodes et al.'s (2014) in-depth interviews in Kenya, Peru and Nepal show that for women it is important to continue to use traditional stoves to maintain traditional food preparation practices, which are considered relevant components of cultural identity [81]. In this regard, Khandelwal et al. (2017) describe the traditional Indian chulha stove as an artifact strictly connected with history and culture [11]. Nguyen et al. (2017) focused on women in Timor-Leste and identified cultural barriers to behavioral change that may explain why some households had bought or been given ICS but were not using them [92]. For example, because of cultural issues, some customers find it more difficult to be patient, to self-train, and to learn how to use a new cooking technology [92]. In addition, in a recent study conducted in Nigeria, Akintan et al. (2018) highlight that "ethnic-specific" traditional norms and taboos have a relevant influence on fuel choice and cooking habits [93].

Not all studies identify a significant relationship between local culture and ICS adoption. For example, Thurber et al. (2014) found little evidence that the attachment to the taste of food cooked on traditional stoves is a significant barrier to adoption of ICS in India and they argue that "barriers to change in cooking habits bay be overstated" [64] (p. 148). Similarly in Burkina-Faso, Bensch et al. (2015) did not find evidence that a clear preference for traditional cooking might be responsible for the underinvestment in ICS [94].

Wang and Bailis (2015) address socio-cultural changes in India and their effect on ICS adoption [39]. In their study, the findings suggest that lower-caste households seem to be abandoning traditional stoves more readily than higher-caste households for "aspirational" reasons. Specifically, the authors argue that the lower castes associate the heavy black smoke of traditional stoves with the religious stigma of them being 'impure'. For this reason, they want to "disassociate themselves from practices that are both literally and symbolically dirty, in favor of practices that are both clean and modern," thus "actively repositioning themselves on the social and the energy 'ladder"' [39] (p. 128,135). Table 2 summarizes the main drivers and barriers identified from the selected papers and the general findings that emerged for each factor. 
Table 2. Factors influencing improved cooking stoves (ICS) adoption.

\begin{tabular}{|c|c|c|}
\hline Drivers and Barriers & References & General Findings \\
\hline \multicolumn{3}{|l|}{ (1) Economic factors } \\
\hline - Income & {$[10,14,28,30,33,37,42,44,50,59,64]$} & $\begin{array}{l}\text { Households with higher income are more likely to adopt ICS than } \\
\text { lower income households. }\end{array}$ \\
\hline - ICS price & {$[7,36,39,43-47,49,50,53,61,72,73,95]$} & $\begin{array}{l}\text { The price of ICS can be a barrier because it is relatively very high } \\
\text { compared to the purchasing power of lower income communities. }\end{array}$ \\
\hline \multicolumn{3}{|l|}{ (2) Socio-demographics } \\
\hline - Age & {$[3,30,35,41,47,59,69]$} & $\begin{array}{l}\text { Younger individuals are more likely to adopt ICS because } \\
\text { they are more open to new technologies and to changing their } \\
\text { cooking behaviors. }\end{array}$ \\
\hline - Education & {$[10,14,15,28,29,35,37,40,59-61,66,68,76]$} & $\begin{array}{l}\text { Highly educated people tend to adopt ICS more frequently than do } \\
\text { less educated people. }\end{array}$ \\
\hline (3) Fuel availability & {$[8,39,64,66,68,72,73]$} & $\begin{array}{l}\text { The intention to adopt ICS decreases when households have free } \\
\text { access to free fuelwood (e.g., near to the forest). }\end{array}$ \\
\hline (4) Attitude toward technology & {$[6,8,9,39,42,49,61,75,77]$} & $\begin{array}{l}\text { Consumers' resistance toward technology is associated with a lower } \\
\text { intention to adopt ICS. }\end{array}$ \\
\hline $\begin{array}{l}\text { (5) Awareness of risks of } \\
\text { traditional cooking stoves vs. } \\
\text { benefits of ICS }\end{array}$ & {$[5,9,27,43-45,49-51,70,72,73,78-82,84,87,88,99]$} & $\begin{array}{l}\text { A low awareness about health and environmental risks associated } \\
\text { to traditional stoves acts as a barrier to the adoption of ICS. } \\
\text { Perceived efficiency, ease of use, and cost savings increase } \\
\text { households' intention to adopt ICS. Maintenance and repairs costs } \\
\text { represent a barrier to adoption. }\end{array}$ \\
\hline (6) Location: urban vs. rural & {$[14,27,37,38,50,89,91]$} & $\begin{array}{l}\text { In urban and suburban areas, the rate of ICS' adoption is higher } \\
\text { than in rural areas because of the scarcity of firewood. }\end{array}$ \\
\hline
\end{tabular}

\subsubsection{Perceptions of Traditional Stoves Versus ICS}

In addition to identifying the key drivers and barriers to clean cooking adoption, the aim of this study was to highlight consumers' perceptions of ICS versus traditional cookstoves. Based on a thematic analysis, four main categories of perceptions emerged from the literature review: convenience and uses, aesthetics, health-related impacts, and environmental impacts. The general findings that emerged with regards to perceptions are summarized in Table 3, and each category is now discussed in more detail.

Table 3. Perceptions of traditional stoves versus ICS.

\begin{tabular}{cll}
\hline Perceptions & \multicolumn{1}{c}{ References } & \multicolumn{1}{c}{ General Findings } \\
\hline Convenience and uses & {$[4,29,39,46,57,78,83,84,87,88,92,95-99]$} & $\begin{array}{l}\text { Households perceive the convenience of ICS in terms of ease of use } \\
\text { and time savings. ICS do not produce enough warmth and light. }\end{array}$ \\
\hline Aesthetics & {$[5,9,49,50,61,75,84,94]$} & $\begin{array}{l}\text { ICS are considered as stylish, well-designed and beautiful; they can } \\
\text { be a status symbol. }\end{array}$ \\
\hline Health-related impacts & {$[43,78,81,84,96,100,101]$} & $\begin{array}{l}\text { Households generally show low awareness about the risks related } \\
\text { to the use of traditional stoves. However, they associate ICS with } \\
\text { the improvement of health (e.g., reduced coughing, eye pain, } \\
\text { allergy, headache) }\end{array}$ \\
\hline Environmental impacts & {$[8,11,36,49,57,65,102,103]$} & $\begin{array}{l}\text { Households generally show low awareness and low concern about } \\
\text { the negative environmental impacts of traditional stoves (e.g., } \\
\text { deforestation and pollution). }\end{array}$ \\
\hline
\end{tabular}

The first category refers to convenience of ICS, mainly in terms of ease of use and time saving $[29,78,84,87,95-97]$. For example, according to the results of laboratory tests conducted by Hanna et al. (2016), it takes less time to boil the same quantity of water with ICS than with traditional 
stoves [83]. In addition, users may need to spend time chopping wood into pieces small enough to fit into the stove's firebox [39,46,92]. Some users consider this extra labor unreasonable [92]. However, households lament the fact that food gets cold faster with ICS than with traditional stoves [88,98].

With regards to possible uses of stoves, the literature shows that traditional stoves meet practical needs other than just cooking. Bielecki and Wingenbach (2014) describe how in rural Guatemala community households value stoves as heat and light sources [4]: traditional stoves offer the possibility for household members to sit around the fire and keep warm, thus responding also to social needs, while ICS are typically higher up and it is not possible to gather around them $[4,98]$. Other scholars suggest that in countries where winters tend to be long and cold some consumers perceive that ICS does not produce enough warmth to heat a space $[57,99]$.

Aesthetics and attractiveness are also characteristics valued by cookstove users [49,61,75,94], especially in urban and peri-urban areas and among young consumers exposed to mass media [50]. Aesthetics is among the benefits of ICS according to households in India [9] and in Burkina-Faso [94]. Urmee and Gyamfi (2014) report that in a cookstove project in Zimbabwe, women valued the aesthetics of ICS and 'social status' ahead of fuel savings [5]. After a field evaluation in western Kenya, women were pleased with the appearance of ICS and found that ICS were stylish, well-designed and beautiful [84].

With regards to health-related impacts, the use of ICS is associated with a reduction in child mortality rates and improved health, especially among women and young girls who cook every day and are more in contact with stoves [100]. However, perceptions of benefits related to the use of ICS may vary according to the respondent, whose awareness of risks associated with the use of traditional cookstoves may be low [78,81]. Person et al. (2012) conducted a qualitative study in rural Kenya. Participants reported that traditional cookstoves emitted a great quantity of smoke that irritated their eyes, nose, and lungs causing illnesses and related expenses for healthcare [43]. In addition, ashes dirtied their food and the house. For example, in a study conducted by Cundale et al. (2017), participants only mentioned perceived health benefits of ICS on 5 occasions out of 109. Such benefits included a reduction in cough and pneumonia and a reduction in eye pain [96], as found also in other studies [101]. In a qualitative study conducted in India, Alam et al. (2016) found that women are generally dissatisfied with traditional stoves and associate them with health problems such as eye redness and irritation, coughing, allergy-type symptoms, chest pain, and accidental burns for both women and children [78]. Loo et al. (2016) explored women's perceptions of ICS after trialing them [84]. Respondents reported that coughing and headaches were either reduced or no longer present after the use of ICS, and they believed that this was the result of smoke reduction.

Traditional cookstoves have severe negative impacts on the environment in terms of deforestation and pollution; ICS use less biomass, easing stress on local forests that are a common source of fuelwood $[36,102,103]$ and reducing the emission of gases that most exacerbate global warming [11]. While these aspects have been recognized in the literature, consumers' concerns about cookstove characteristics and their environmental effects in a broad sense (i.e., not limited to indoor air pollution) emerged in very few studies [49,57]. For example, Martin et al. (2013) report that several village health volunteers and key informants mentioned environmental sustainability as important cookstove attributes [49]. Van del Kroon et al. (2014) found that people (men more than women) are aware of increasing pressures on their natural environment; however, they also comment that the cost of degrading the environment does not enter consumers' decision making because of "a poverty-related short term planning horizon" (p. 246) [8]. Jeuland et al. (2015) also found that environmental risk awareness is higher regarding the local environment and forests than for outdoor air pollution and/or climate change [65].

\section{Discussion}

This review of the literature indicates a growing interest in clean cooking from a consumer behavior perspective, with a sharp increase in such publications since 2006. Most journals in which 
the selected articles were published fall into the subject area of energy, environment, medicine, social sciences and economics, while marketing and consumer journals seem to pay still limited attention to this topic.

With respect to the first research question regarding factors affecting ICS adoption, there is general agreement about some drivers. In particular, higher income, urban location, a positive attitude toward technology, and awareness about health risks seem to enhance the adoption of ICS. Conversely, low income, together with high perceived price of ICS, rural location, resistance toward new technology, and low awareness about the negative outcomes of the use of traditional stoves represent a barrier to the adoption of ICS. In addition, several scholars highlight that women tend to be more likely than are men to buy ICS, even though they often lack sufficient authority and economic power in the household to act on their preference. For some other variables, the studies reviewed in this analysis present contrasting results. For example, with regards to education, many scholars agree that a higher level of education positively influences the intention to purchase more sustainable cooking systems, although other scholars have found that an open mind rather than education as such may affect consumers' choices. In addition, while younger age is mostly associated with a higher propensity to purchase ICS, some studies found that older age increases the probability of ICS adoption. The effects of family size and fuel availability on ICS adoption are also unclear. With respect to cookstove characteristics, poor design of ICS (e.g., in terms of size) may represent a barrier to adoption. Another important theme that emerged from the analysis concerns social and cultural influences. In particular, households seem to be greatly affected by the role of their peers (e.g., neighbors) or opinion leaders (e.g., village leaders) in the adoption of ICS, implying that social norms play a crucial role in shaping consumer behavior in this context. Culture also affects cooking choices because the stove is often linked to cultural identity [81], and households value the ability to cook traditional meals and respect their particular taste. In addition, in certain cultures gathering around a traditional stove provides social interaction that is not facilitated by ICS.

With regards to the second research question, consumers' perceptions of the characteristics of traditional stoves versus ICS develop around four main topics: convenience, aesthetics, health-related impacts, and environmental impacts. With respect to convenience, ICS are regarded as more efficient and time saving than traditional stoves, even though they cannot respond as well to other practical needs such as heating or lighting, and do not serve as a social gathering point. Some studies suggest that the aesthetics of ICS is important in consumer decisions in that ICS are perceived as more attractive than traditional stoves, and can be a status symbol [39]. With respect to health-related impacts of traditional stoves, awareness remains low among households; even lower is awareness about environmental impacts. Nevertheless, some studies highlight that users are dissatisfied with traditional stoves because they have several drawbacks, such as causing eye irritation, cough and burns.

The findings of this review suggest several practical implications for ICS producers and policy makers such as governments, foundations, non-governmental organizations, and international institutions. From a managerial perspective, it is worth considering that in their decision-making process, consumers respond to marketing stimuli (e.g., advertising campaigns and price policies) and other external stimuli (e.g., the political, economic, social or technological context) according to their personal characteristics. A well-established consumer behavior model classifies the main variables influencing consumer behavior as cultural, social, personal and psychological variables [104]. The drivers and barriers identified in this systematic literature review, as well as the perceptions that emerged regarding ICS, can be reconnected to this model. For example, cultural variables include local culture, tradition in the preparation of certain dishes, and the use of the traditional stove as a point for social aggregation. Social variables include the influence exerted by community leaders or neighbors in consumer choices related to cooking systems, as well as the role of family members in affecting households' decision making. Personal variables refer mainly to socio-demographics such as gender, age, education, occupation, and income, while psychological variables concern the motivations for purchasing ICS, perceptions about ICS versus traditional stoves, and attitudes toward 
technology. Adopting this model of consumer variables helps to focus attention on the identification of key practical implications for ICS manufacturers and policy makers, as summarized in Table 4.

Table 4. Managerial and policy implications.

\begin{tabular}{lll}
\hline \multicolumn{1}{c}{ Implications for ICS Manufacturers } & \multicolumn{1}{c}{ Implications for Policy Makers } \\
\hline - Market segmentation & - & $\begin{array}{l}\text { Economic incentives and facilitated access to credit } \\
\text { Communication campaigns to raise people's awareness } \\
\text { about risks related to traditional stoves vs. benefits of ICS }\end{array}$ \\
- Product innovation and adaptation & Product appeal & - $\begin{array}{l}\text { Education programs to facilitate learning and increase } \\
\text { sustained usage of ICS }\end{array}$ \\
- Multiple prices strategies & - $\begin{array}{l}\text { Community-based initiatives (e.g., with "clean cooking } \\
\text { ambassadors") }\end{array}$ \\
- Mundle of products and services & Marketing strategies directed to peer groups & Fostering collaboration and synergies with other actors
\end{tabular}

Central role of women

\section{Implications for ICS Manufacturers}

Manufacturers should focus on market analysis to segment customers and develop an effective marketing mix. The literature review has shown that ICS are not successful when their design does not take into account other important cultural and social needs, even if they are more efficient. In this sense, preliminary segmentation studies based on cultural variables might help to understand how consumers differ, for example in terms of needs, perceptions, and willingness to adopt new technologies [76]. It is important to remember that the adoption of new technologies such as ICS, "is a complex social process that requires critical shifts in culture and behavior" [11] (p. 18). Therefore, before designing products, firms should understand what the traditional stove represents in the local culture, what are the traditional foods, and what are the types of usage of stoves in that specific culture.

Product innovation should be based on an analysis of the demand and directed to respond not only to functional, practical needs (e.g., having a certain number of fires, keeping heat for a certain amount of time), but also to symbolic needs related to the individuals' social and psychological sphere. In this regard, innovation should be focused on making the product more desirable and meeting demand. This goal is difficult to reach because ICS are used in an inconspicuous (i.e., private) consumption domain; nonetheless, as shown in previous research [39], ICS can represent status symbols in certain communities. Thus to achieve this objective, communication activities such as advertising campaigns or public relations activities are fundamental.

As lack of clean cooking specifically affects low-income countries, affordable prices are needed for market penetration. Selling to the bottom of the pyramid implies high logistics and marketing costs, but also creates the opportunity to reach a large number of potential customers in a context where competition is usually less fierce than in mature markets [105]. To increase revenue and cover costs in low-income markets, high volumes of sales must be reached. However, recent studies suggest that to increase margins and be competitive in the long term, manufacturers should instead adopt a multiple prices approach rather than simply a low-price policy. For example, they could offer basic solutions at affordable prices to specific market segments with low purchasing power, while also offering other product lines at higher prices aimed at satisfying the needs of well-off households. Manufacturers could also pursue a strategy aimed at selling a bundle of products and services rather than single goods, thus creating "customer-specific or industry-specific 'solutions' that are more competitive than generally available standalone products" (Cusumano et al., 2015, p. 559) [106]. This approach can also increase perceived customer value and enrich consumer experience [107]. For example, some solar-powered lights also provide other functionalities, such as the capacity to recharge cell phones, in their manufacture [108].

The literature review revealed that peers can have a strong impact on consumers' decisions to adopt ICS. Therefore, manufacturers should consider directing their marketing efforts to peer groups, 
such as household primary cooks, health professionals, or mothers of young children. Peers could act as referrals, share knowledge, and spread positive word-of-mouth within their social networks.

Finally, manufacturers could collaborate with retailers to organize trials, develop pre-sale consultancies, and offer after-sale assistance to support customers throughout all phases of the purchasing and consumption process.

\section{Implications for Policy Makers}

Some implications can also be derived for policy makers. In several ICS programs, policy makers address personal constraints related to low income in order to overcome economic barriers to the purchase of ICS. Incentives and facilitated access to credit can be useful to enhance ICS adoption among low-income households in the short term. However, to be effective in the long run, psychological variables such as motivation for purchasing ICS should be taken into account. Accordingly, incentives and credit should be supported by specific communication activities to increase awareness about the health and environmental drawbacks of traditional cooking stoves and motivate consumers to move to more sustainable solutions [32]. The risk of merely incentive-based adoption of ICS or donor funding initiatives is that they can easily result in disadoption.

Policy makers should provide customer education programs to facilitate learning, adoption, and sustained usage of ICS [109]. In the marketing literature, customer education is described as "a process including a number of educational activities aimed at improving the consumers' ability (i.e., attitudes, knowledge or skills) to better purchase, use and appreciate goods and services as well as protect their rights and interests" (Brunetti et al., 2016, p. 396) [110]. Considering that replacing traditional stoves with more sustainable cooking systems requires a significant attitude and behavioral change, customer education initiatives could represent a lever for gradually improving households' confidence with a new technology and new type of stove usage.

Policy makers should also work at a community level, involving opinion leaders or creating new figures such as "clean cooking ambassadors". In the branding literature, a brand ambassador can be a customer (e.g., a member of a brand community), a celebrity (e.g., a testimonial), or an employee (e.g., sales person) $[111,112]$. Borrowing from this concept, policy makers could identify a clean cooking "expert" and "enthusiast" (e.g., a customer, celebrity, or professional in a certain field) willing to share knowledge, best practices, experience, and skills to promote the use of clean cooking systems in communities. Furthermore, these ambassadors could contribute to creating an attractive positioning for ICS and encourage households to adopt sustainable cooking solutions [64].

Fostering collaboration between actors in the ICS supply chain should also be a priority for policy makers. Such collaboration could involve, for example, energy providers, ICS manufacturers, retailers, health organizations and other associations. Only a joint effort by these organizations will reduce the divide in the use of clean cooking systems between developed and developing countries.

Finally, both manufacturers and policy makers should reflect about the role of women in households and society. Women are the primary users of stoves and the ones who suffer most from the drawbacks of traditional cooking stoves. However, they often do not have the economic and decisional power to decide about the adoption of ICS [3]. In addition, they might be subject to cultural pressure to keep up the standards of traditional authentic food. The involvement of women in customer education programs, communication campaigns, and trials is, therefore, of the utmost importance to increase adoption and sustained use of ICS.

To conclude, access to and affordability of technology might be the first step toward the diffusion of ICS; however, to support the widespread adoption and use of ICS it is necessary to approach customers with a less technical, more culture-specific and personalized approach.

\section{Conclusions}

Lack of access to clean energy is still a reality in many developing countries and millions of people, especially women and children, suffer the consequences of the use of biomass solid fuels for 
cooking which also has broader consequences for the global environment [2,12]. Enhancing the use of more efficient ad safer cooking systems among households is, therefore, an issue of vital importance. While most published articles about ICS focus on technical aspects such as stove performance and characteristics, or on the negative effects of indoor air pollution both on peoples' health and on the environment, this study adopts a different perspective by putting the customer at the center of its analysis. Specifically, this research has systematically reviewed the body of literature about ICS from a consumer perspective. By identifying the main factors affecting ICS adoption and exploring customers' perceptions, this review contributes to the understanding of consumer behavior in a still under-researched field. In addition, the findings provide useful insights and practical implications that can help policy makers and companies enhance ICS adoption and use among households.

Nevertheless, some limitations should be acknowledged. First, data collection was limited to peer-reviewed articles present in Scopus and WoS. Even though these databases provide a wide coverage of the academic literature, future studies could expand the data collection to grey literature (e.g., via Google Scholar) to include recent conference contributions as well as industry and government reports. A second limitation is linked to the keywords used. Further research could attempt to add other keywords to expand the results. Third, even though a rigorous analysis was conducted to reduce subjectivity in the identification of the themes for drivers and barriers as well as consumers' perceptions, future studies could work on categorization to identify other sub-themes or higher-order categories. Further reviews could also analyze in-depth differences between countries in consumer behavior to identify peculiarities and common patterns in ICS adoption.

From the findings, it is also possible to identify some future research directions for scholars wishing to improve the understanding of consumers' choices with regards to cooking systems. First, the results concerning drivers and barriers could be used to develop different communication campaigns and test their effectiveness for ICS adoption. Second, future research could investigate more in depth the social desirability of ICS as a status symbol to identify other variables that could affect ICS adoption. Finally, it would be important to increase knowledge about customer satisfaction with the use of different types of ICS to identify the strengths and weaknesses associated with each technology and how they could be addressed.

Author Contributions: All authors contributed substantially to the paper. Conceptualization: V.V., F.T. and R.S.; Methodology: V.V.; Data collection: V.V. and R.S.; Data analysis and interpretation: V.V., R.S. and F.T.; Writing: V.V. (Sections 1, 2, 3.2.1 and 4); R.S. (Sections 3.1 and 3.2.2); F.T. (Section 5).

Funding: This research received no external funding.

Conflicts of Interest: The authors declare no conflict of interest.

\section{References}

1. International Energy Agency. World Energy Outlook 2016; International Energy Agency: Pari, France, 2016.

2. Lim, J.; Petersen, S.; Schwarz, D.; Schwarz, R.; Maru, D. A rights-based approach to indoor air pollution. Health Hum. Rights 2013, 15, 160-167. [PubMed]

3. Mohapatra, S.; Simon, L. Intra-household bargaining over household technology adoption. Rev. Econ. Househ. 2017, 15, 1263-1290. [CrossRef]

4. Bielecki, C.; Wingenbach, G. Rethinking improved cookstove diffusion programs: A case study of social perceptions and cooking choices in rural Guatemala. Energy Policy 2014, 66, 350-358. [CrossRef]

5. Urmee, T.; Gyamfi, S. A review of improved Cookstove technologies and programs. Renew. Sustain. Energy Rev. 2014, 33, 625-635. [CrossRef]

6. Bonan, J.; Pareglio, S.; Tavoni, M. Access to modern energy: A review of barriers, drivers and impacts. Environ. Dev. Econ. 2017, 22, 491-516. [CrossRef]

7. Hewitt, J.; Ray, C.; Jewitt, S.; Clifford, M. Finance and the improved cookstove sector in East Africa; Barriers and opportunities for value-chain actors. Energy Policy 2018, 117, 127-135. [CrossRef] 
8. Van der Kroon, B.; Brouwer, R.; Van Beukering, P.J.H.H.; Van der Kroon, B.; Brouwer, R.; Van Beukering, P.J.H.H. The impact of the household decision environment on fuel choice behavior. Energy Econ. 2014, 44, 236-247. [CrossRef]

9. Rehman, I.H.; Kar, A.; Arora, A.; Pal, R.; Singh, L.; Tiwari, J.; Singh, V.K. Distribution of improved cook stoves: Analysis of field experiments using strategic niche management theory. Sustain. Sci. 2012, 7, 227-235. [CrossRef]

10. Jan, I.; Ullah, S.; Akram, W.; Khan, N.P.; Asim, S.M.; Mahmood, Z.; Ahmad, M.N.; Ahmad, S.S. Adoption of improved cookstoves in Pakistan: A logit analysis. Biomass Bioenergy 2017, 103, 55-62. [CrossRef]

11. Khandelwal, M.; Hill, M.E., Jr.; Greenough, P.; Anthony, J.; Quill, M.; Linderman, M.; Udaykumar, H.S. Why Have Improved Cook-Stove Initiatives in India Failed? World Dev. 2017, 92, 13-27. [CrossRef]

12. Ruiz-Mercado, I.; Masera, O.; Zamora, H.; Smith, K.R. Adoption and sustained use of improved cookstoves. Energy Policy 2011, 39, 7557-7566. [CrossRef]

13. Denyer, D.; Tranfield, D. Producing a Systematic Review. In The SAGE Handbook of Organizational Research Methods; American Psychological Association: Washington, DC, USA, 2009; pp. 671-689, ISBN 9781412931182.

14. Lewis, J.J.; Pattanayak, S.K. Who adopts improved fuels and cookstoves? A systematic review. Environ. Health Perspect. 2012, 120, 637-645. [CrossRef] [PubMed]

15. Puzzolo, E.; Pope, D.; Stanistreet, D.; Rehfuess, E.A.; Bruce, N.G. Clean fuels for resource-poor settings: A systematic review of barriers and enablers to adoption and sustained use. Environ. Res. 2016, 146, $218-234$. [CrossRef] [PubMed]

16. Merli, R.; Preziosi, M.; Acampora, A. How do scholars approach the circular economy? A systematic literature review. J. Clean. Prod. 2018, 178, 703-722. [CrossRef]

17. Masi, D.; Day, S.; Godsell, J. Supply Chain Configurations in the Circular Economy: A Systematic Literature Review. Sustainability 2017, 9, 1602. [CrossRef]

18. Gimenez, C.; Tachizawa, E.M. Extending sustainability to suppliers: A systematic literature review. Supply Chain Manag. 2012, 17, 531-543. [CrossRef]

19. M. Tachizawa, E.; Yew Wong, C. Towards a theory of multi-tier sustainable supply chains: A systematic literature review. Supply Chain Manag. Int. J. 2014, 19, 643-663. [CrossRef]

20. De Medeiros, J.F.; Ribeiro, J.L.D.; Cortimiglia, M.N. Success factors for environmentally sustainable product innovation: A systematic literature review. J. Clean. Prod. 2014, 65, 76-86. [CrossRef]

21. Lubberink, R.; Blok, V.; van Ophem, J.; Omta, O. Lessons for Responsible Innovation in the Business Context: A Systematic Literature Review of Responsible, Social and Sustainable Innovation Practices. Sustainability 2017, 9, 721. [CrossRef]

22. Fischer, D.; Stanszus, L.; Geiger, S.; Grossman, P.; Schrader, U. Mindfulness and sustainable consumption: A systematic literature review of research approaches and findings. J. Clean. Prod. 2017, 162, 544-558. [CrossRef]

23. Orzes, G.; Moretto, A.M.; Ebrahimpour, M.; Sartor, M.; Moro, M.; Rossi, M. United Nations Global Compact: Literature review and theory-based research agenda. J. Clean. Prod. 2018, 177, 633-654. [CrossRef]

24. David, R.J.; Han, S.-K. A Systematic Assessment of the Empirical Support for Transaction Cost Economics. Strateg. Manag. J. 2004, 25, 39-58. [CrossRef]

25. Jia, F.; Jiang, Y. Sustainable Global Sourcing: A Systematic Literature Review and Bibliometric Analysis. Sustainability 2018, 10, 595. [CrossRef]

26. Siva, V.; Gremyr, I.; Bergquist, B.; Garvare, R.; Zobel, T.; Isaksson, R. The support of Quality Management to sustainable development: A literature review. J. Clean. Prod. 2016, 138, 148-157. [CrossRef]

27. Manibog, F.R. Improved cooking stoves in developing countries: Problems and opportunities. Annu. Rev. Energy 1984, 9, 199-227. [CrossRef]

28. Lee, L.Y.T. Household energy mix in Uganda. Energy Econ. 2013, 39, 252-261. [CrossRef]

29. Brooks, N.; Bhojvaid, V.; Jeuland, M.A.; Lewis, J.J.; Patange, O.; Pattanayak, S.K. How much do alternative cookstoves reduce biomass fuel use? Evidence from North India. Resour. Energy Econ. 2016, 43, 153-171. [CrossRef]

30. Akomolafe, J.K.; Ogunleye, E.O. Determinants of cooking fuel choices in urban Nigeria. J. Environ. Manag. Tour. 2017, 8, 168-182. [CrossRef] 
31. Onyeneke, R.U.; Nwajiuba, C.U.; Mmagu, C.J.; Aligbe, J.O.; Igberi, C.O. Performance and determinants of adoption of improved cook-stoves in farming communities in Benue and Kaduna States of Nigeria. World Rev. Sci. Technol. Sustain. Dev. 2017, 13, 276-297. [CrossRef]

32. Piedrahita, R.; Dickinson, K.L.; Kanyomse, E.; Coffey, E.; Alirigia, R.; Hagar, Y.; Rivera, I.; Oduro, A.; Dukic, V.; Wiedinmyer, C.; et al. Assessment of cookstove stacking in Northern Ghana using surveys and stove use monitors. Energy Sustain. Dev. 2016, 34, 67-76. [CrossRef]

33. Miah, M.D.; Al Rashid, H.; Shin, M.Y. Wood fuel use in the traditional cooking stoves in the rural floodplain areas of Bangladesh: A socio-environmental perspective. Biomass Bioenergy 2009, 33, 70-78. [CrossRef]

34. Pine, K.; Edwards, R.; Masera, O.; Schilmann, A.; Marrón-Mares, A.; Riojas-Rodríguez, H. Adoption and use of improved biomass stoves in Rural Mexico. Energy Sustain. Dev. 2011, 15, 176-183. [CrossRef]

35. Pandey, V.L.; Chaubal, A. Comprehending household cooking energy choice in rural India. Biomass Bioenergy 2011, 35, 4724-4731. [CrossRef]

36. Vahlne, N.; Ahlgren, E.O. Energy Efficiency at the Base of the Pyramid: A System-Based Market Model for Improved Cooking Stove Adoption. Sustainability 2014, 6, 8679-8699. [CrossRef]

37. Andadari, R.K.; Mulder, P.; Rietveld, P. Energy poverty reduction by fuel switching. Impact evaluation of the LPG conversion program in Indonesia. Energy Policy 2014, 66, 436-449. [CrossRef]

38. Vitali, F.; Vaccari, M. Socio-economic survey as a support tool during the scaling up of improved stoves in the Logone Valley (Chad/Cameroon). Sustainability 2014, 6, 1427-1447. [CrossRef]

39. Wang, Y.; Bailis, R. The revolution from the kitchen: Social processes of the removal of traditional cookstoves in Himachal Pradesh, India. Energy Sustain. Dev. 2015, 27, 127-136. [CrossRef]

40. Alem, Y.; Hassen, S.; Kohlin, G. Adoption and disadoption of electric cookstoves in urban Ethiopia: Evidence from panel data. Resour. Energy Econ. 2014, 38, 110-124. [CrossRef]

41. Onyeneke, R.U.; Nwajiuba, C.U.; Mmagu, C.J.; Aligbe, J.O.; Uwadoka, C.O.; Igberi, C.O.; Amadi, M.U. Impact of adoption of improved cook-stove on different components of household welfare in rural communities in Nigeria: The case of Save80 cook-stove in Kaduna. Environ. Prog. Sustain. Energy 2017. [CrossRef]

42. Wickramasinghe, A. Energy access and transition to cleaner cooking fuels and technologies in Sri Lanka: Issues and policy limitations. Energy Policy 2011, 39, 7567-7574. [CrossRef]

43. Person, B.; Loo, J.D.; Owuor, M.; Ogange, L.; Jefferds, M.E.D.; Cohen, A.L. "It is good for my family's health and cooks food in a way that my heart loves": Qualitative findings and implications for scaling up an improved cookstove project in rural Kenya. Int. J. Environ. Res. Public Health 2012, 9, 1566-1580. [CrossRef] [PubMed]

44. Kulindwa, Y.J.; Lokina, R.; Ahlgren, E.O. Driving forces for households' adoption of improved cooking stoves in rural Tanzania. Energy Strateg. Rev. 2018, 20, 102-112. [CrossRef]

45. Barnes, B.; Rosenbaum, J.; Mehta, S.; Williams, K.N.; Jagoe, K.; Graham, J. Behavior change communication: A key ingredient for advancing clean cooking. J. Health Commun. 2015, 20, 3-5. [CrossRef] [PubMed]

46. Wallmo, K.; Jacobson, S.K. A social and environmental evaluation of fuel-efficient cook-stoves and conservation in Uganda. Environ. Conserv. 1998, 25, 99-108. [CrossRef]

47. Muneer, S.E.T.; Mohamed, E.W.M. Adoption of biomass improved cookstoves in a patriarchal society: An example from Sudan. Sci. Total Environ. 2003, 307, 259-266. [CrossRef]

48. Troncoso, K.; Castillo, A.; Merino, L.; Lazos, E.; Masera, O.R. Understanding an improved cookstove program in rural Mexico: An analysis from the implementers' perspective. Energy Policy 2011, 39, 7600-7608. [CrossRef]

49. Martin, S.L.; Arney, J.K.; Mueller, L.M.; Kumakech, E.; Walugembe, F.; Mugisha, E. Using formative research to design a behavior change strategy to increase the use of improved cookstoves in Peri-urban Kampala, Uganda. Int. J. Environ. Res. Public Health 2013, 10, 6920-6938. [CrossRef] [PubMed]

50. Kapfudzaruwa, F.; Fay, J.; Hart, T. Improved cookstoves in Africa: Explaining adoption patterns. Dev. South. Afr. 2017, 34, 548-563. [CrossRef]

51. Maré, M.; Annegarn, H.J. The Use of Willingness to Pay in Determining Customer Preferences for Improved Flame-Based Cookstove Features in Two South African Study Areas. Soc. Mar. Q. 2017, 23, 335-353. [CrossRef]

52. Bensch, G.; Peters, J. The intensive margin of technology adoption-Experimental evidence on improved cooking stoves in rural Senegal. J. Health Econ. 2015, 42, 44-63. [CrossRef] [PubMed] 
53. Atmadja, S.S.; Sills, E.O.; Pattanayak, S.K.; Yang, J.-C.; Patil, S. Explaining environmental health behaviors: Evidence from rural India on the influence of discount rates. Environ. Dev. Econ. 2017, 22, 229-248. [CrossRef]

54. Kumar, P.; Kaushalendra Rao, R.; Reddy, N.H.H. Sustained uptake of LPG as cleaner cooking fuel in rural India: Role of affordability, accessibility, and awareness. World Dev. Perspect. 2016, 4, 33-37. [CrossRef]

55. Pal, R.C.; Rehman, I.H. Efficient cookstove technology for improving the kitchen environment and livelihood for women in rural India. Int. J. Ambient Energy 2008, 29, 137-148. [CrossRef]

56. Jerneck, A.; Olsson, L. A smoke-free kitchen: Initiating community based co-production for cleaner cooking and cuts in carbon emissions. J. Clean. Prod. 2013, 60, 208-215. [CrossRef]

57. Bhojvaid, V.; Jeuland, M.; Kar, A.; Lewis, J.J.; Pattanayak, S.K.; Ramanathan, N.; Ramanathan, V.; Rehman, I.H. How do People in Rural India Perceive Improved Stoves and Clean Fuel? Evidence from Uttar Pradesh and Uttarakhand. Int. J. Environ. Res. Public Health 2014, 11, 1341-1358. [CrossRef] [PubMed]

58. Wang, Y.; Corson, C. The making of a 'charismatic' carbon credit: Clean cookstoves and 'uncooperative' women in western Kenya. Environ. Plan. A 2015, 47, 2064-2079. [CrossRef]

59. Mamuye, F.; Lemma, B.; Woldeamanuel, T. Emissions and fuel use performance of two improved stoves and determinants of their adoption in Dodola, southeastern Ethiopia. Sustain. Environ. Res. 2018, 28, 32-38. [CrossRef]

60. Wilson, D.L.; Coyle, J.; Kirk, A.; Rosa, J.; Abbas, O.; Adam, M.I.; Gadgil, A.J. Measuring and Increasing Adoption Rates of Cookstoves in a Humanitarian Crisis. Environ. Sci. Technol. 2016, 50, 8393-8399. [CrossRef] [PubMed]

61. Troncoso, K.; Castillo, A.; Masera, O.; Merino, L. Social perceptions about a technological innovation for fuelwood cooking: Case study in rural Mexico. Energy Policy 2007, 35, 2799-2810. [CrossRef]

62. Takama, T.; Tsephel, S.; Johnson, F.X. Evaluating the relative strength of product-specific factors in fuel switching and stove choice decisions in Ethiopia. A discrete choice model of household preferences for clean cooking alternatives. Energy Econ. 2012, 34, 1763-1773. [CrossRef]

63. Vahlne, N.; Ahlgren, E.O. Policy implications for improved cook stove programs-A case study of the importance of village fuel use variations. Energy Policy 2014, 66, 484-495. [CrossRef]

64. Thurber, M.C.; Phadke, H.; Nagavarapu, S.; Shrimali, G.; Zerriffi, H. “Oorja” in India: Assessing a large-scale commercial distribution of advanced biomass stoves to households. Energy Sustain. Dev. 2014, 19, 138-150. [CrossRef] [PubMed]

65. Jeuland, M.A.; Bhojvaid, V.; Kar, A.; Lewis, J.J.; Patange, O.; Pattanayak, S.K.; Ramanathan, N.; Rehman, I.H.; Soo, J.S.T.; Ramanathan, V. Preferences for improved cook stoves: Evidence from rural villages in north India. Energy Econ. 2015, 52, 287-298. [CrossRef]

66. Poddar, M.; Chakrabarti, S. Indoor air pollution and women's health in India: An exploratory analysis. Environ. Dev. Sustain. 2016, 18, 669-677. [CrossRef]

67. Kersten, W.C.; Long, N.H.; Diehl, J.C.; Crul, M.R.M. Influence of Context Variation on Quality of Solutions: Experiences with Gasifier Stoves. Procedia Manuf. 2017, 8, 487-494. [CrossRef]

68. Joshi, J.; Bohara, A.K.A.K. Household preferences for cooking fuels and inter-fuel substitutions: Unlocking the modern fuels in the Nepalese household. Energy Policy 2017, 107, 507-523. [CrossRef]

69. Clark, S.; Carter, E.; Shan, M.; Ni, K.; Niu, H.; Tseng, J.T.W.; Pattanayak, S.K.; Jeuland, M.; Schauer, J.J.; Ezzati, M.; et al. Adoption and use of a semi-gasifier cooking and water heating stove and fuel intervention in the Tibetan Plateau, China. Environ. Res. Lett. 2017, 12. [CrossRef]

70. Jagger, P.; Jumbe, C. Stoves or sugar? Willingness to adopt improved cookstoves in Malawi. Energy Policy 2016, 92, 409-419. [CrossRef] [PubMed]

71. Thomas, E.A.; Tellez-Sanchez, S.; Wick, C.; Kirby, M.; Zambrano, L.; Abadie Rosa, G.; Clasen, T.F.; Nagel, C. Behavioral Reactivity Associated With Electronic Monitoring of Environmental Health Interventions-A Cluster Randomized Trial with Water Filters and Cookstoves. Environ. Sci. Technol. 2016, 50, 3773-3780. [CrossRef] [PubMed]

72. Patel, S.; Khandelwal, A.; Leavey, A.; Biswas, P. A model for cost-benefit analysis of cooking fuel alternatives from a rural Indian household perspective. Renew. Sustain. Energy Rev. 2016, 56, 291-302. [CrossRef]

73. Mudombi, S.; Nyambane, A.; von Maltitz, G.P.; Gasparatos, A.; Johnson, F.X.; Chenene, M.L.; Attanassov, B. User perceptions about the adoption and use of ethanol fuel and cookstoves in Maputo, Mozambique. Energy Sustain. Dev. 2018, 44, 97-108. [CrossRef] 
74. Troncoso, K.; Armendariz, C.; Alatorre, S. Improved cook stove adoption and impact assessment: A proposed methodology. Energy Policy 2013, 62, 637-645. [CrossRef]

75. Goodwin, N.J.; O’Farrell, S.E.; Jagoe, K.; Rouse, J.; Roma, E.; Biran, A.; Finkelstein, E.A. Use of behavior change techniques in clean cooking interventions: A review of the evidence and scorecard of effectiveness. J. Health Commun. 2015, 20, 43-54. [CrossRef] [PubMed]

76. Johnson, M.A.; Chiang, R.A. Quantitative guidance for stove usage and performance to achieve health and environmental targets. Environ. Health Perspect. 2015, 123, 820-826. [CrossRef] [PubMed]

77. Goswami, A.; Bandyopadhyay, K.R.; Kumar, A. Exploring the nature of rural energy transition in India: Insights from case studies of eight villages in Bihar. Int. J. Energy Sect. Manag. 2017, 11, 463-479. [CrossRef]

78. Alam, A.; Tawale, N.; Patel, A.; Dibley, M.J.; Jadhao, S.; Raynes-Greenow, C. Household Air Pollution Intervention Implications: Findings from Qualitative Studies and a Field Trial of Clean Cookstoves in Two Rural Villages in India. Int. J. Environ. Res. Public Health 2016, 13, 893. [CrossRef] [PubMed]

79. Kumar, P.; Chalise, N.; Yadama, G.N. Dynamics of sustained use and abandonment of clean cooking systems: Study protocol for community-based system dynamics modeling. Int. J. Equity Health 2016, 15, 70. [CrossRef] [PubMed]

80. Malla, S. Household energy consumption patterns and its environmental implications: Assessment of energy access and poverty in Nepal. Energy Policy 2013, 61, 990-1002. [CrossRef]

81. Rhodes, E.L.; Dreibelbis, R.; Klasen, E.; Naithani, N.; Baliddawa, J.; Menya, D.; Khatry, S.; Levy, S.; Tielsch, J.M.; Jaime Miranda, J.; et al. Behavioral attitudes and preferences in cooking practices with traditional open-fire stoves in Peru, Nepal, and Kenya: Implications for improved cookstove interventions. Int. J. Environ. Res. Public Health 2014, 11, 10310-10326. [CrossRef] [PubMed]

82. Catalán-Vázquez, M.; Fernández-Plata, R.; Martínez-Briseño, D.; Pelcastre-Villafuerte, B.; Riojas-Rodríguez, H.; Suárez-González, L.; Pérez-Padilla, R.; Schilmann, A. Factors that enable or limit the sustained use of improved firewood cookstoves: Qualitative findings eight years after an intervention in rural Mexico. PLoS One 2018, 13, e0193238. [CrossRef] [PubMed]

83. Hanna, R.; Duflo, E.; Greenstone, M. Up in Smoke: The Influence of Household Behavior on the Long-Run Impact of Improved Cooking Stoves. Am. Econ. J. Econ. Policy 2016, 8, 80-114. [CrossRef]

84. Loo, J.D.; Hyseni, L.; Ouda, R.; Koske, S.; Nyagol, R.; Sadumah, I.; Bashin, M.; Sage, M.; Bruce, N.; Pilishvili, T.; et al. User perspectives of characteristics of improved cookstoves from a field evaluation in Western Kenya. Int. J. Environ. Res. Public Health 2016, 13. [CrossRef] [PubMed]

85. Gebreegziabher, Z.; van Kooten, G.C.; van Soest, D.P. Technological innovation and dispersion: Environmental benefits and the adoption of improved biomass cookstoves in Tigrai, northern Ethiopia. Energy Econ. 2017, 67, 337-345. [CrossRef]

86. Tigabu, A. Factors associated with sustained use of improved solid fuel cookstoves: A case study from Kenya. Energy Sustain. Dev. 2017, 41, 81-87. [CrossRef]

87. Keese, J.; Camacho, A.; Chavez, A. Follow-up study of improved cookstoves in the Cuzco region of Peru. Dev. Pract. 2017, 27, 26-36. [CrossRef]

88. Hollada, J.; Williams, K.N.; Miele, C.H.; Danz, D.; Harvey, S.A.; Checkley, W. Perceptions of improved biomass and liquefied petroleum gas stoves in Puno, Peru: Implications for promoting sustained and exclusive adoption of clean cooking technologies. Int. J. Environ. Res. Public Health 2017, 14. [CrossRef] [PubMed]

89. Manjula, M.; Gopi, G. Universal access to clean cooking energy and the need for an inclusive policy: Evidence from analysis of cooking fuel use in Odisha and Tamil Nadu. Decision 2017, 44, 193-207. [CrossRef]

90. Hou, B.D.; Tang, X.; Ma, C.; Liu, L.; Wei, Y.M.; Liao, H. Cooking fuel choice in rural China: Results from microdata. J. Clean. Prod. 2017, 142, 538-547. [CrossRef]

91. Danlami, A.H.; Applanaidu, S.D.; Islam, R. An analysis of household cooking fuel choice: A case of Bauchi State, Nigeria. Int. J. Energy Sect. Manag. 2018, 12, 265-283. [CrossRef]

92. Nguyen, T.T.P.T. Women's adoption of improved cook stoves in Timor-Leste: Challenges and opportunities. Dev. Pract. 2017, 27, 1126-1132. [CrossRef]

93. Akintan, O.; Jewitt, S.; Clifford, M. Culture, tradition, and taboo: Understanding the social shaping of fuel choices and cooking practices in Nigeria. Energy Res. Soc. Sci. 2018, 40, 14-22. [CrossRef] 
94. Bensch, G.; Grimm, M.; Peters, J. Why do households forego high returns from technology adoption? Evidence from improved cooking stoves in Burkina Faso. J. Econ. Behav. Organ. 2015, 116, 187-205. [CrossRef]

95. Barnes, D.F.; Openshaw, K.; Smith, K.R.; Vanderplas, R. The design and diffusion of improved cooking stoves. World Bank Res. Obs. 1993, 8, 119-141. [CrossRef]

96. Cundale, K.; Thomas, R.; Malaya, J.K.; Havens, D.; Mortimer, K.; Conteh, L. A health intervention or a kitchen appliance? Household costs and benefits of a cleaner burning biomass-fuelled cookstove in Malawi. Soc. Sci. Med. 2017, 183, 1-10. [CrossRef] [PubMed]

97. Honkalaskar, V.H.; Bhandarkar, U.V.; Sohoni, M. Development of a fuel efficient cookstove through a participatory bottom-up approach. Energy. Sustain. Soc. 2013, 3. [CrossRef]

98. Thompson, L.M.; Diaz-Artiga, A.; Weinstein, J.R.; Handley, M.A. Designing a behavioral intervention using the COM-B model and the theoretical domains framework to promote gas stove use in rural Guatemala: A formative research study. BMC Public Health 2018, 18, 253. [CrossRef] [PubMed]

99. Njenga, M.; Iiyama, M.; Jamnadass, R.; Helander, H.; Larsson, L.; De Leeuw, J.; Neufeldt, H.; Röing De Nowina, K.; Sundberg, C. Gasifier as a cleaner cooking system in rural Kenya. J. Clean. Prod. 2016, 121, 208-217. [CrossRef]

100. Bhanot, J.; Jha, V. Moving towards tangible decision-making tools for policy makers: Measuring and monitoring energy access provision. Energy Policy 2012, 47, 64-70. [CrossRef]

101. Burwen, J.; Levine, D.I. A rapid assessment randomized-controlled trial of improved cookstoves in rural Ghana. Energy Sustain. Dev. 2012, 16, 328-338. [CrossRef]

102. Usmani, F.; Steele, J.; Jeuland, M. Can economic incentives enhance adoption and use of a household energy technology? Evidence from a pilot study in Cambodia. Environ. Res. Lett. 2017, 12. [CrossRef]

103. Brown, E.; Leary, J.; Davies, G.; Batchelor, S.; Scott, N. eCook: What behavioural challenges await this potentially transformative concept? Sustain. Energy Technol. Assessments 2017, 22, 106-115. [CrossRef]

104. Armstrong, G.; Kotler, P. Marketing: An Introduction 12th Edition. 2015. Available online: https://www.pearson.com/us/higher-education/product/Armstrong-Marketing-An-Introduction-12thEdition/9780133451276.html?tab=overview (accessed on 21 November 2018).

105. Karnani, A. The Mirage of Marketing to the Bottom of the Pyramid: How the Private Sector Can Help Alleviate Poverty. Calif. Manage. Rev. 2007, 49, 90-111. [CrossRef]

106. Cusumano, M.A.; Kahl, S.J.; Suarez, F.F. Services, industry evolution, and the competitive strategies of product firms. Strateg. Manag. J. 2015. [CrossRef]

107. Stampacchia, P.; Colurcio, M.; Coppola, M. Integrated value-in-use: Looking for a new strategic orientation. Sinergie Ital. J. Manag. 2016, 34, 159-175.

108. Simanis, E. Reality check at the bottom of the pyramid. Harv. Bus. Rev. 2012, 90, 120-125.

109. Brunetti, F.; Bonfanti, A. Effects of customer education in terms of customer perceived value: The role of customer evaluation skills. Sinergie Ital. J. Manag. 2015, 33, 219-238.

110. Brunetti, F.; Bonfanti, A.; Vigolo, V. Empowering customer education: A research agenda for marketing studies. In Proceedings of the 9th Annual Euromed Academy of Business (EMAB) Conference "Innovation, Entrepreneurship and Digital Ecosystems", Warsaw, Poland, 14-16 September 2016; pp. 393-405.

111. Fisher-Buttinger, C.; Vallaster, C. Brand Ambassadors: Strategic Diplomats or Tactical Promoters? In Marketing Metaphors and Metamorphosis; Palgrave Macmillan: London, UK, 2008; pp. 132-145, ISBN 9780230227538.

112. Schmidt, H.J.; Baumgarth, C. Strengthening internal brand equity with brand ambassador programs: Development and testing of a success factor model. J. Brand Manag. 2018. [CrossRef]

(C) 2018 by the authors. Licensee MDPI, Basel, Switzerland. This article is an open access article distributed under the terms and conditions of the Creative Commons Attribution (CC BY) license (http:/ / creativecommons.org/licenses/by/4.0/). 